\title{
Pembentukan Temporal Association Rules Menggunakan Algoritma Apriori (Studi Kasus:Toko Batik Diyan Solo)
}

\author{
Annisa Mauliani ${ }^{*}$, Sri Hartati ${ }^{2}$, Aina Musdholifah ${ }^{3}$ \\ ${ }^{1}$ Prodi S2/S3 Ilmu Komputer FMIPA UGM \\ ${ }^{2}$ Jurusan Ilmu Komputer dan Elektronika, FMIPA UGM, Yogyakarta \\ e-mail: *19annisamauliani1990@gmail.com, ${ }^{2}$ shartati@ugm.ac.id, ${ }^{3}$ aina_m@ugm.ac.id
}

\begin{abstract}
Abstrak
Penelitian ini terdapat penambahan aspek waktu pada hasil Association Rules Mining. Aspek waktu yang digunakan dalam penelitian ini adalah tanggal transaksi. Bentuk informasi yang dihasilkan dari penambahan aspek waktu dalam Association Rules Mining dikenal dengan Temporal Association Rules Mining. Data yang digunakan untuk penelitian ini adalah data transaksi penjualan di Toko Batik Diyan Solo.

Dalam penelitian ini, Algoritma Apriori digunakan untuk pembentukan Temporal Association Rules. Hasil dari penelitian ini menunjukkan Algoritma Apriori dan Temporal Association Rules dapat digunakan untuk menggali informasi. Hasil pengujian ini dapat digunakan untuk bahan pertimbangan dalam memperkirakan penambahan stok barang pada event tertentu bagi pihak manajerial Batik Diyan, karena pada hasil Temporal Association Rules terdapat keterangan tambahan mengenai event. Sehingga pada hasil Temporal Association Rules dapat diketahui, Temporal Association Rules tersebut terjadi pada saat event apa saja.

Di Hari Raya Idul Fitri Tahun 2013 dan Hari Raya Idul Fitri Tahun 2014 pada parameter nilai minsup 10\%, mintempsup 5, minconf 50\%, menghasilkan Temporal Association Rules yang berbeda. Pada Hari Raya Idul Fitri Tahun 2013, tidak menghasilkan Temporal Association Rules. Sedangkan pada Hari Raya Idul Fitri Tahun 2014 menghasilkan Temporal Association Rules dengan nilai support yang terbesar $14 \%$, yaitu $\{B L B P\} \rightarrow$ $\{H P C K\}$
\end{abstract}

Kata kunci-penjualan, temporal association rules, Apriori, data mining

\section{Abstract}

In this study the adding of time aspect on association rules mining result was used. The aspect of time that was used in this study was date of transactions. The information that was resulted from time aspect adding in association rules mining was known as temporal association rules mining..

In this study, Apriori Algorithm was used for the forming of temporal association rules. This result which show Algorithm Apriori and Temporal Association Rules can be used to get more information about Temporal Association Rules. The Result of this examination can be used for decision support for manager. Because the result of Temporal Association Rules have explanation about event. So from the result of Temporal Association Rules can be knowing, the Temporal Association Rules happened at the time of event.

In Ramadan Idul Fitri 2013 and Ramadan Idul Fitri 2014 with parameter assess minsup 10\%, mintempsup 5, minconf 50\%, resulting different Temporal Association Rules. In Ramadan Idul Fitri 2013, no resulting Temporal Association Rules. While is on Ramadan Idul Fitri 2014 resulting Temporal Association Rules with the biggest value of support 14\%, that is $\{B L B P\} \rightarrow\{H P C K\}$.

Keywords - sale, temporal association rules, apriori and data mining 


\section{PENDAHULUAN}

Saat ini telah banyak toko batik di Indonesia, terutama di Solo. Salah satu toko batik yang Serada di Solo adalah toko Batik Diyan. Persaingan yang ketat dalam sentra usaha toko batik sangat terasa sekali di Solo. Para pengusaha toko batik di wilayah Solo dituntut untuk lebih kreatif dan inovatif dalam pengembangan usaha toko batiknya. Salah satu strategi yang dapat dilakukan dalam pengembangan usaha toko batik adalah pengadaan barang yang sering laku terjual secara bersamaan.

Dari uraian permasalahan diatas, maka peneliti menganalisis pola data penjualan kedalam bentuk Temporal Association Rules. Tujuan dari pembuatan Temporal Association Rules adalah untuk mengetahui barang yang sering laku terjual secara bersamaan. Karena di Toko Batik Diyan Solo belum terdapat system untuk mengetahui barang yang laku secara bersamaan. Perlunya penambahan aspek waktu dalam hasil aturan asosiasi karena walaupun barang yang terdapat di Batik Diyan telah tersusun rapi dalam rak, namun belum dapat di ketahui pola barang yang terjual terkait dengan waktu. Kondisi di lapangan menunjukkan beberapa item barang tersedia dalam kondisi berlebih, sedangkan untuk item barang yang lain nampak sedikit tersedia. Oleh karena itu diperlukan hasil aturan asosiasi yang memperhatikan aspek waktu. Misal ketika Hari Raya Idul Fitri Tahun 2013 Temporal Association Rules yang dihasilkan berbeda jika di banding Hari Raya Idul Fitri Tahun 2014. Terdapat pembelian perlengkapan ibadah pada masa lebaran, namun hal tersebut tidak Nampak terjadi pada bulan lain selain Bulan Ramadhan.

Penelitian yang telah dilakukan [1] [2] menggunakan Algoritma Apriori untuk menghasilkan Temporal Association Rules. Namun, hasil Temporal Association Rule yang dihasilkan belum menginformasikan kejadian atau peristiwa yang terjadi dalam interval waktu yang sama event. Untuk itu, penelitian ini menggunakan Algoritma Apriori dengan memperhatikan event untuk Temporal Association Rules yang dihasilkan, pada data penjualan di Toko Batik Diyan Solo.

\section{METODE PENELITIAN}

Pada penelitian ini melewati tahap metode penelitian pengumpulan data, pengolahan data, perancangan sistem, pembuatan sistem, evaluasi dan perbaikan sistem, dan pengujian sistem.

\subsection{Perancangan Sistem}

Menentukan batasan support, dan kandidat itemset dengan Algoritma Apriori, kemudian menghitung support temporal dan confidence. Selanjutnya menambahkan informasi terkait waktu berupa tanggal transaksi sebagai temporal dengan TAR. Hasil akhir berupa temporal rules. Hal tersebut dapat dilihat pada Gambar 1. 


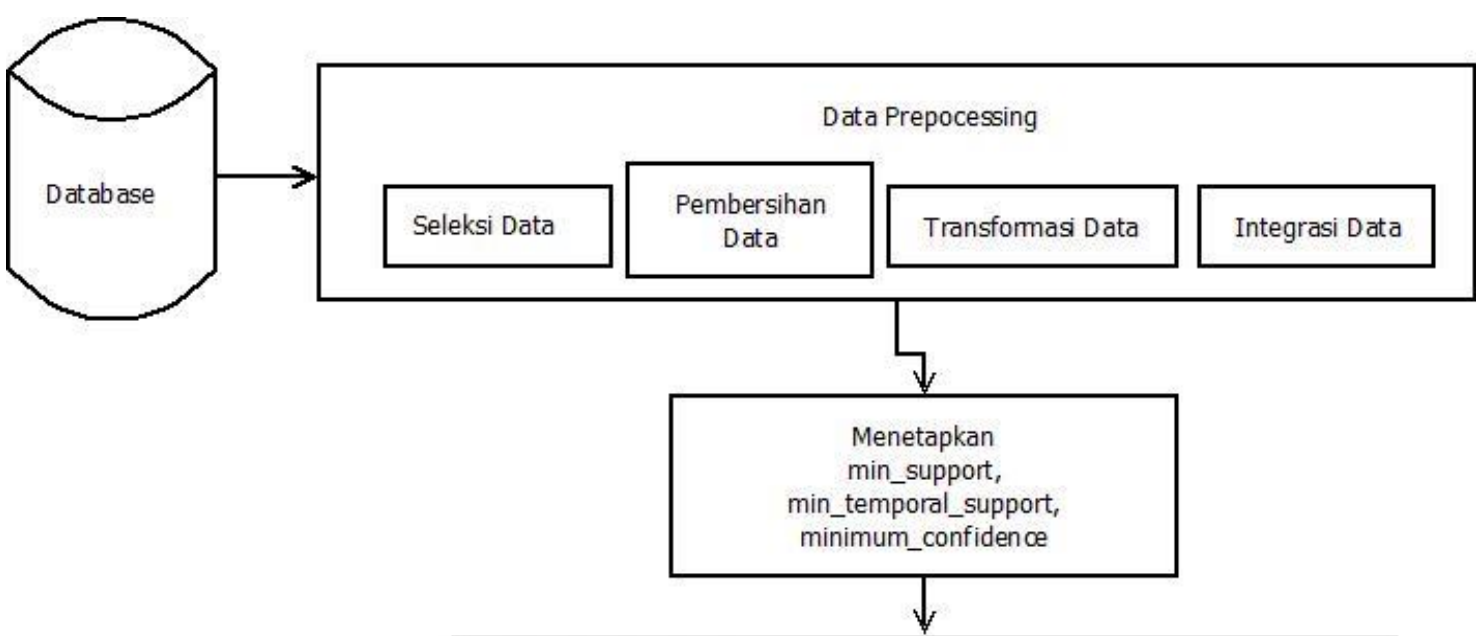

Proses pembentukan

candidat frequent itemset

Mencari lifespan dari tiap-tiap item dan itemset

Menghitung nilai support masing-masing item dan itemset, dengan memperhatikan lifespannya

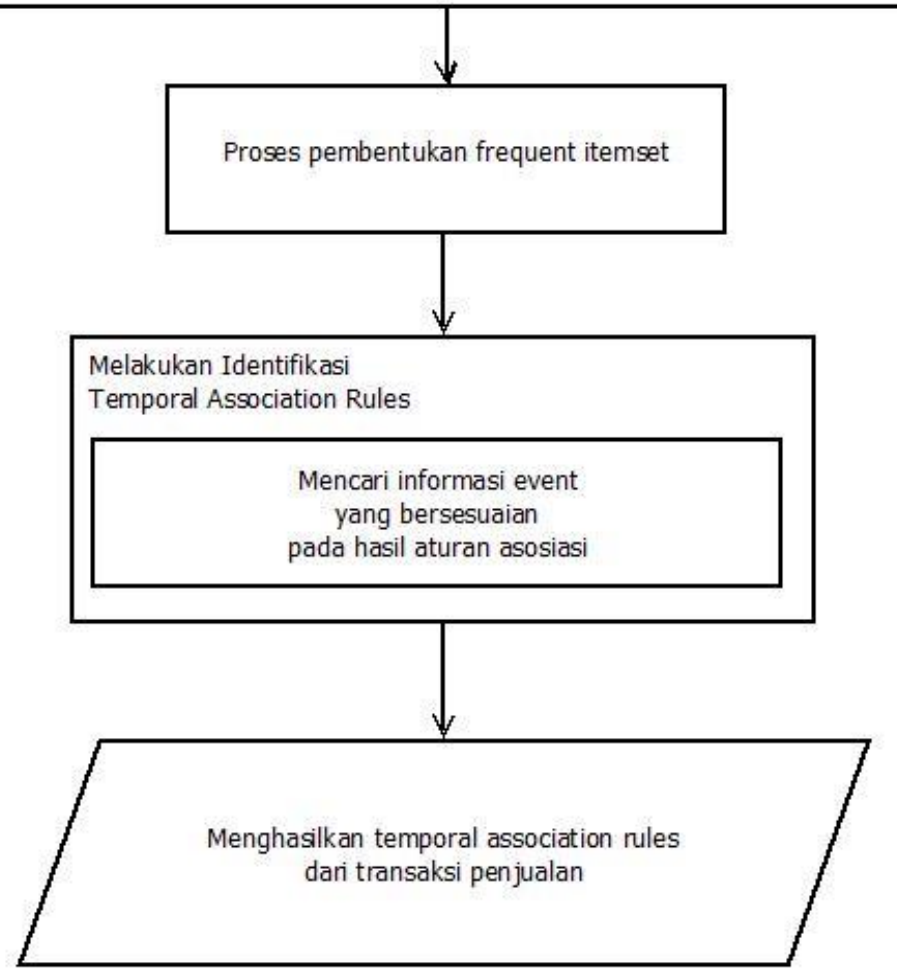

Gambar 1 Rancangan sistem Algoritma Apriori Temporal Association Rule untuk analisa pola penjualan toko Batik Diyan Solo

\subsection{Perancangan proses pembentukan frequent itemset dengan Algoritma Apriori}

Perancangan proses pembentukan frequent itemset dengan Algoritma Apriori dapat dilihat pada Gambar 2. Langkah awal dalam pencarian frequent itemset yang sudah 
mengandung aspek waktu dengan Algoritma Apriori adalah pengaturan nilai parameter minimum support dan minimum temporal support. Mencari Candidat Frequent Itemset dari data transaksi penjualan dalam database (db_tar). Tiap-tiap C $k$-Itemset dicari nilai lifespan (LS). Nilai durasi lifespan digunakan untuk mencari nilai support dari tiap-tiap Ck-Itemset. Nilai durasi lifespan dihitung hanya pada tanggal-tanggal yang terdapat transaksi saja. Pencarian nilai support itemset $>1$ bisa di dapatkan menggunakan persamaan (1). Pencarian nilai support itemset $>1$ bisa di dapatkan menggunakan persamaan (2)

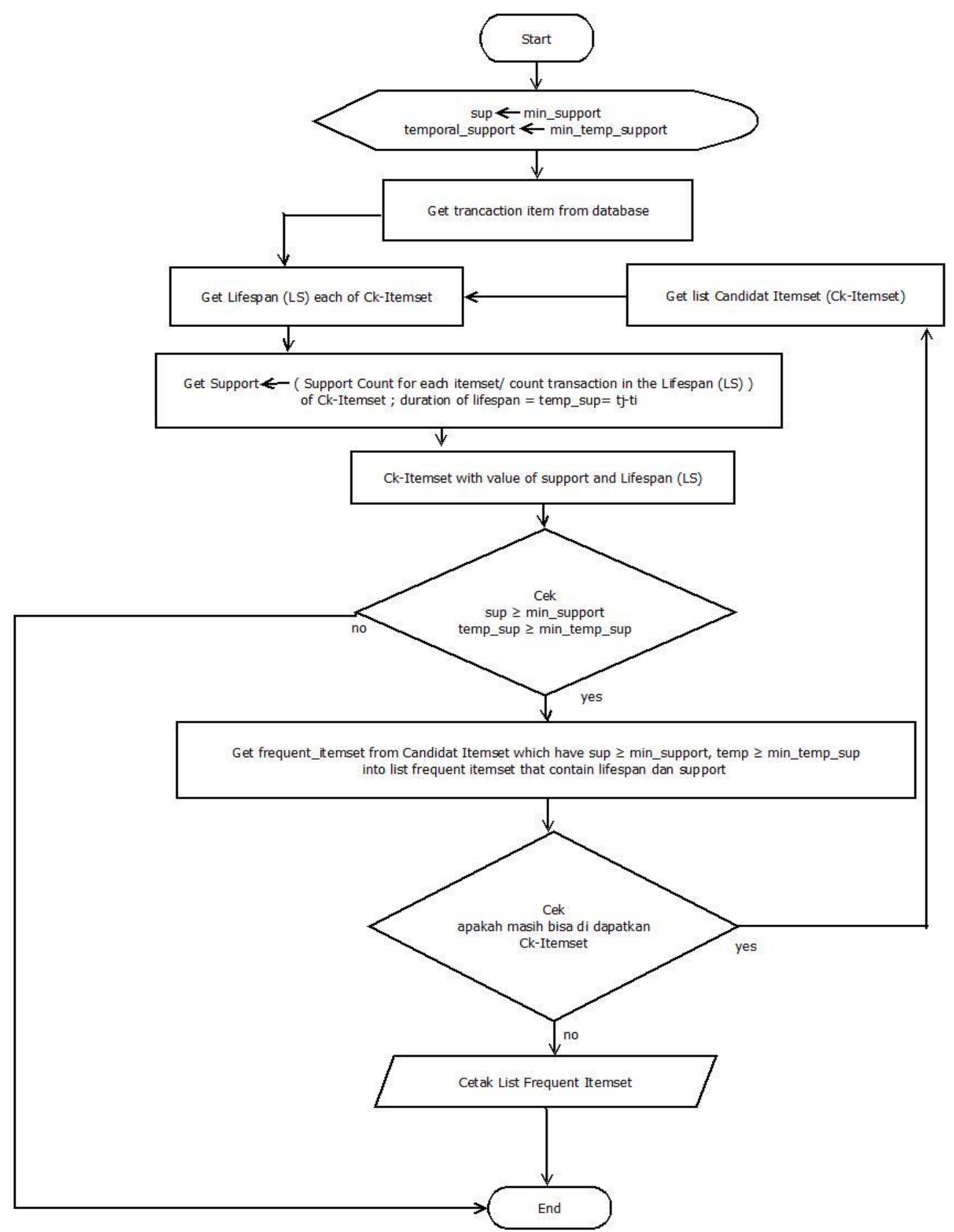

Gambar 2 flowchat dari proses pembentukan frequent itemset dengan Algoritma Apriori. 
Support $A \cup B=\frac{\text { Jumlah transaksi yang mengandung item } A \text { dan } B}{\mid \text { lifispan } A \cup B \mid}$

$\left.s\left(\mathrm{X},{ }_{x}, d\right)=|\mathrm{V}(\mathrm{X}, d)| /\left.\right|^{d_{l x \mid}}\right)$

Tanggal yang tidak terdapat transaksi tidak terhitung sebagai durasi lifespan. Ketika nilai support dari tiap-tiap Ck-Itemset didapatkan, maka list $C k$-Itemset telah lengkap berisi nilai support dan Lifespan. List Ck-Itemset yang sudah lengkap berisi nilai support dan Lifespan, dilakukan pengecekan nilai sup $\geq$ min_support dan nilai temporal_support $\geq$ min_temporal_support dari tiap-tiap Ck-itemset. Dimana temporal support dapat memenuhi nilai minimum temporal support, jika $\mathrm{Tj}-\mathrm{Ti} \geq$ min_temporal_support. Jika Ck-itemset memenuhi nilai sup $\geq$ min_support dan nilai temporal_support $\geq$ min_temporal_support, maka menjadi frequent itemset ( $k$-itemset). Akan tetapi jika tidak, maka akan mengalami prune candidat itemset sehingga item yang mengalami prune, tidak menjadi frequent itemset.

Dari hasil frequent itemset, dilakukan pengecekan apakah masih bisa didapatkan $C k$ Itemset. Jika ya maka terjadi perulangan langkah dalam pembuatan $C k$-Itemset. Jika dari hasil frequent itemset tidak lagi dapat dibuat $C k$-Itemset maka proses pembuatan frequent itemset telah selesai. Dalam pembuatan candidat itemset, dilakukan join antar item dari hasil frequent itemset sebelumnya [3]. Pembuatan Gambar 2 merupakan flowchat dari proses pembentukan frequent itemset dengan Algoritma Apriori yang telah melibatkan waktu.

\subsection{Perancangan Temporal Association Rules}

Perancangan Temporal Association Rules dengan Algoritma Apriori ditunjukkan pada Gambar 3. Tahap pertama melakukan pembacaan hasil frequent itemset yang telah dihasilkan oleh Algoritma Apriori. Kemudian melakukan pengecekan apakah frequent itemset > 1-itemset. Jika ya, maka dapat dilakukan pembentukan association rules. Kombinasi rules yang mungkin muncul dalam aturan asosiasi dari tiap-tiap hasil frequent itemset dapat dicari dengan menggunakan rumus $2^{k}-2$. Setelah ditemukan kombinasi rules yang mungkin terjadi, kemudian menghitung nilai confidence dari tiap-tiap rules yang ada dan mencari lifespan (LS) dari tiap-tiap rules. Dimana nilai lifespan dari rule merupakan nilai lifespan dari frequent itemset yang telah didapatkan. Dalam menghitung nilai confidence selalu memperhatikan kembali nilai support dari item bagian kiri dari rules.

Jika rules $\mathrm{X} \rightarrow \mathrm{Y}$, maka nilai support dari item $\mathrm{X}$ harus nilai support dari nilai interval yang sama dengan nilai interval itemset $\{\mathrm{X}, \mathrm{Y}\}$. Lebih detail dapat ditunjukkan pada persamaan (3).

$$
\operatorname{Conf}\left(X \rightarrow Y,\left[t_{1}, t_{2}\right], d\right)=\frac{s\left(X \cup Y_{l} l_{X \cup Y}, d\right)}{s\left(X, l_{X \cup Y}, d\right)}
$$

Ketika nilai confidence dan lifespan dari semua kombinasi kemungkinan rules sudah didapatkan, dilakukan pengecekan nilai confidence $\geq$ min_conf. Jika ya, maka rules tersebut merupakan Strong Rule. Jika tidak, maka rules tersebut belum dapat dinyatakan Strong Rule untuk hasil asosiasi. Setelah didapatkan hasil Association Rules, dilakukan lagi pengece[-kan apakah didalam interval tanggal pada rules tersebut terdapat event. Jika ya, maka dilakukan

Pembentukan Temporal Association Rules Menggunakan Algoritma ... (Annisa Mauliani) 
penambahan informasi pada rules, bahwa rules tersebut "terjadi pada event ...". Jika tidak maka pada rules tersebut tidak terdapat penambahan informasi mengenai event.

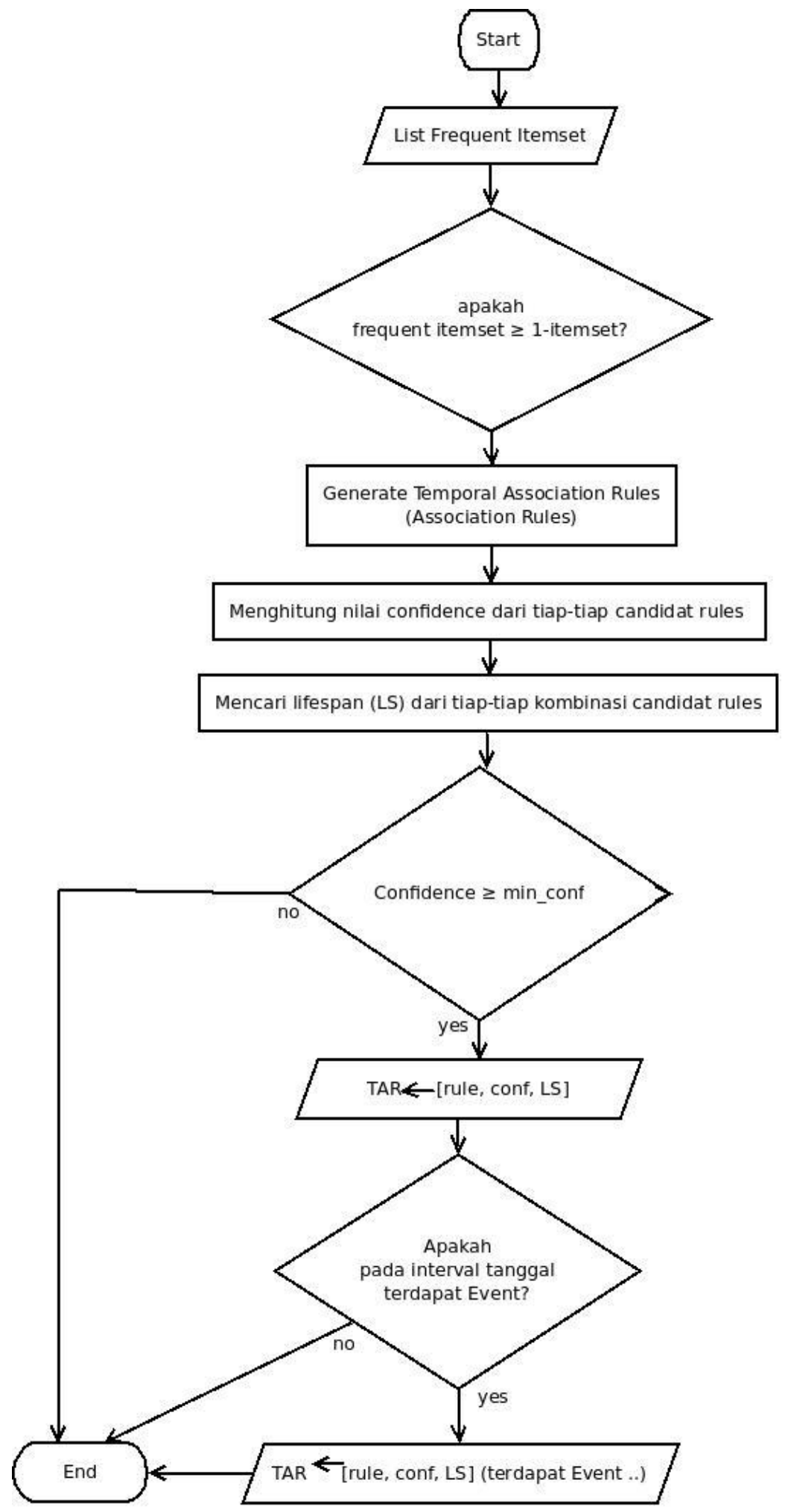

Gambar 3 Perancangan Temporal association rule 


\subsection{Algoritma Apriori dalam Pembentukan Temporal Association Rules}

Lebih lanjut diberikan ilustrasi dalam pencarian frequent itemsets yang memodifikasi Algoritma Apriori. Berikut ilustrasi perhitungan frequent itemsets yang memodifikasi Algoritma Apriori. Dapat dilihat pada Gambar 4.

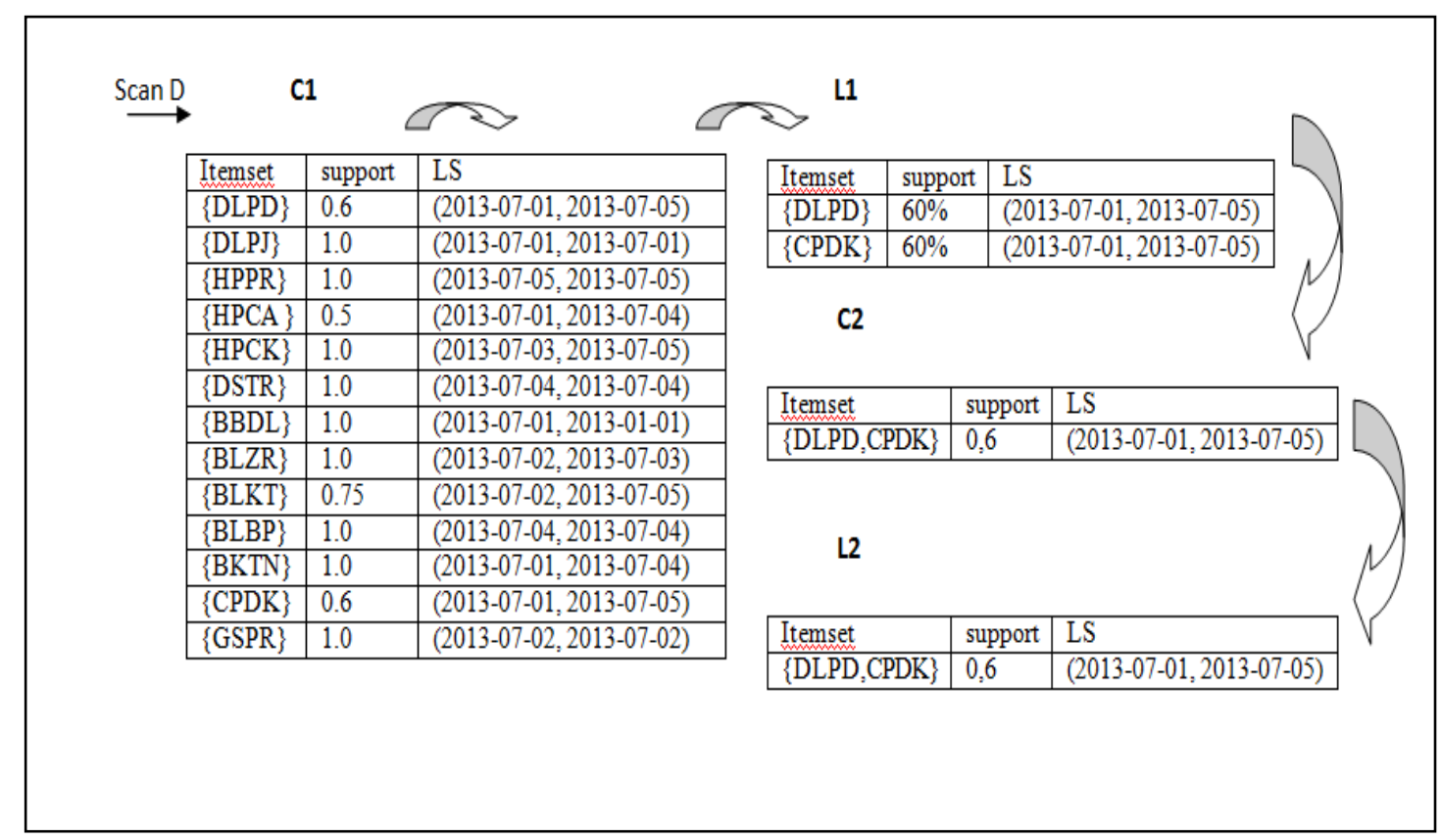

Gambar 4 Ilustrasi Perhitungan Temporal Frequent Itemsets

Dari Gambar 4 dapat kita lihat, dari database D, dilakukan scanning untuk menghasilkan candidat itemset. C1 merupakan candidat frequent 1-itemset. C2 merupakan candidat frequent 2-itemset. L1 merupakan hasil temporal frequent 1-itemset. Telah didapatkan Nilai $\mathrm{s}(\mathrm{DLPD}, \mathrm{x}, \mathrm{D})=\mid \mathrm{V}\left(\mathrm{DLPD}, \mathrm{D}|/| D l_{x} \mid\right)=3 / 5=0,6$. Maka item $\{\mathrm{DLPD}\}$ merupakan temporal frequent 1-itemset. L2 merupakan hasil temporal frequent 2-itemset. Nilai lifespan dari item, dicari dari dalam database. Nilai support item $X$ dicari dengan rumus $s(X, l x, d)=|V(X, d)|$ $/ d_{l x \mid}$. Pencarian frequent itemsets dari contoh Gambar 4, berhenti di L2, karena itemset yang ada sudah tidak dapat dilakukan join untuk mendapatkan frequent itemset berikutnya.

\section{HASIL DAN PEMBAHASAN}

Dari hasil pengujian dapat dirangkum yang ditunjukkan pada Tabel 1, dimana pola barang yang dibeli bersamaan muncul secara konsisten untuk data penjualan pada interval waktu tertentu. Pada Tabel 1 nilai support 30\% untuk temporal association rule interval 1 tahun. Yaitu HPCA $\rightarrow$ HPCK, dan HPCK $\rightarrow$ HPCA. 
Tabel 1 Hasil temporal association rules dalam 1 tahun

\begin{tabular}{|c|c|c|c|c|c|c|c|}
\hline Skema & \multicolumn{3}{|c|}{ Parameter } & \multicolumn{3}{|c|}{} \\
\hline & $\begin{array}{l}\text { Min } \\
\text { Sup }\end{array}$ & $\begin{array}{l}\text { Min } \\
\text { Tem } \\
\text { Sup }\end{array}$ & $\begin{array}{c}\text { Min } \\
\text { Conf }\end{array}$ & Temporal Rules & Sup & Conf & Interval \\
\hline 6 & $25 \%$ & 5 & $50 \%$ & HPCA $\rightarrow$ HPCK & $8 \%$ & $53,33 \%$ & $\begin{array}{c}12 \text { month } \\
\text { (19 Mei 2013 - } \\
19 \text { Mei 2014) }\end{array}$ \\
\cline { 1 - 6 } & $25 \%$ & 5 & $50 \%$ & HPCK $\rightarrow$ HPCA & $8 \%$ & $50 \%$ & \\
\hline
\end{tabular}

Selain itu, pada Tabel 2, adalah hasil untuk interval 1 bulan pada bulan Agustus 2013 dan interval 1 bulan Bulan Juli 2014. Nampak temporal association rules yang terbentuk berbeda.

Tabel 2 Hasil temporal association rules Hari Raya Idul Fitri

\begin{tabular}{|c|c|c|c|c|c|c|c|}
\hline \multirow[t]{2}{*}{ Skema } & \multicolumn{3}{|c|}{ Parameter } & \multirow[b]{2}{*}{ Temporal Rules } & \multirow[b]{2}{*}{ Sup } & \multirow[b]{2}{*}{ Conf } & \multirow[b]{2}{*}{ Interval } \\
\hline & $\begin{array}{l}\text { Min } \\
\text { Sup }\end{array}$ & $\begin{array}{l}\text { Min } \\
\text { Tem } \\
\text { Sup }\end{array}$ & $\begin{array}{l}\text { Min } \\
\text { Conf }\end{array}$ & & & & \\
\hline 7 & $9 \%$ & 14 & $50 \%$ & $\mathrm{HPCA} \rightarrow \mathrm{HPCK}$ & $9 \%$ & $75 \%$ & $\begin{array}{c}1 \text { month } \\
\text { ( } 1 \text { Agustus } \\
2013-31 \\
\text { Agustus } \\
2013)\end{array}$ \\
\hline 8 & $10 \%$ & 5 & $50 \%$ & $\mathrm{BLBP} \rightarrow \mathrm{HPCK}$ & $\begin{array}{l}14 \\
\%\end{array}$ & $100 \%$ & $\begin{array}{c}1 \text { month } \\
\text { ( } 1 \text { Juli 2014- } \\
\text { 31 Juli 2014) }\end{array}$ \\
\hline
\end{tabular}

Tabel 2 tersebut menunjukkan perbedaan hasil temporal association rules pada bulan yang terdapat event Hari Raya tahun sebelumnya. Artinya, jenis item dari itemset penghasil temporal association rules pada bulan yang terdapat event Hari Raya Idul Fitri tahun sebelumnya berhasil dijadikan sebagai item pemancing barang lain yang belum laku terjual supaya laku terjual.

Selain itu, pada parameter minsup $10 \%$, mintempsup 5, dan minconf 50\%, pada $1-31$ Juli 2014 menghasilkan rules yang berbeda dengan bulan Agustus 2013. Pada bulan Agustus 2013 tidak menghasilkan rules. 


\section{KESIMPULAN}

Setelah proses penelitian dilakukan, diperoleh beberapa kesimpulan tentang hasil sebagai berikut:

1. Algoritma Apriori dan Metode Temporal Association Rules dapat menghasilkan Temporal Association Rules.

2. Jika nilai parameter mintempsup berbeda, maka akan menghasilkan temporal association rules yang berbeda.

3. Itemset HPCK menjadi sebuah itemset yang selalu terjual pada Hari Raya Idul Fitri tahun 2013 dan Hari Raya Idul Fitri tahun 2014.

\section{SARAN}

Penelitian ini memiliki beberapa kekurangan sehingga perlu perbaikan untuk pengembangan penelitian dimasa depan, terutama dibidang temporal association rules:

1. Data transaksi penjualan yang diperoleh tidak terdapat jam transaksi. Diharapkan pada penelitian berikutnya mampu lebih detail karena bisa mengetahui pola belanja berdasarkan waktu pagi, siang atau malam. Sehingga temporal rules yang dihasilkan selain tanggal transaksi juga terdapat waktu transaksi.

2. Untuk penelitian selanjutnya dapat menggunakan Algoritma Lain seperti Algoritma FPGrowth. 


\section{DAFTAR PUSTAKA}

[1] Ale, J.M., dan Rossi, G.H., 2000, An Approach to Discovering Temporal Association Rules, in Proceedings of The 2000 ACM Symposium on Applied Computing, pp. 294 300 .

[2] Liang, Z., Xinming T., Lin L. dan Wenliang J., 2005, Temporal Association Rule Mining Based on T-Apriori Algorithm and Its Typical Application. Proc. of Int. Symposiumon Spatio-temporal Modelling Spatial Reasoning,analysis, Data mining and Data Fusion.

[3] Agrawal, R., dan Srikant, R., 1994, Fast Algorithm for Mining Association Rules, Proceedings 20th International Confrence VLDB, Santiago Chile, pp. 487 - 499 